\title{
Non linear analysis of vibrations generated by a contact with friction
}

\author{
Anissa Meziane* — Laurent Baillet** \\ * Laboratoire de Mécanique Physique, CNRS UMR 5469 \\ Université Bordeaux 1, 351 Cours de la Libération \\ F-33405 TALENCE cedex \\ a.meziane@lmp-u-bordeaux1.fr \\ ** Laboratoire de Géophysique Interne et Tectonophysique, CNRS \\ Université Joseph Fourier, BP 53 F-38041 Grenoble cedex 9 \\ lbaillet@ujf-grenoble.fr
}

\begin{abstract}
The aim of this paper is to study vibrations generated at contact with friction for two different applications. The first one is an investigation of friction-induced vibrations of a beam-on-beam system in contact with friction. For this study the complementary use of linear and nonlinear analyses drives to the understanding of physical phenomenon induced in these vibrations. The second parts consists in investigating numerically dynamic rupture of a bimaterial interface. The numerical Finite Element model is composed of two homogeneous and isotropic elastic solids which are brought in contact with friction by remote normal compression and shear traction. The rupture is nucleated by decreasing instantaneously the friction coefficient to zero at nucleation area. The properties of the obtained ruptures (velocity, generated waves, interface state...) are analyzed.

RÉSUMÉ. L'objectif de ce papier est d'étudier, sur deux exemples, les vibrations macroscopiques et microscopiques générées au niveau d'un contact frottant. Le premier exemple traite des vibrations auto-entretenues générées au niveau du contact avec frottement de deux poutres. Dans cette application, l'utilisation complémentaire d'une analyse non linéaire temporelle et d'une analyse linéaire de stabilité permet de comprendre les phénomènes physiques mis en jeu. Le second exemple est une étude numérique de la rupture dynamique de l'interface entre deux solides isotropes de matériaux différents. Le modèle éléments finis est composé de deux solides déformables en contact avec frottement initialement précontraint en compression et en cisaillement. La rupture est initiée en diminuant brutalement le coefficient de frottement. Les propriétés des ruptures obtenues (vitesse, ondes générées, type de ruptures) sont analysées.
\end{abstract}

KEYWORDS: contact with friction, dynamic, finite element.

MOTS-CLÉS : contact frottant, dynamique, éléments finis.

DOI:10.3166/EJCM.19.305-316 (c) 2010 Lavoisier, Paris

EJCM - 19/2010. Giens 2009, pages 305 to 316 


\section{Introduction}

In this paper we focussed on dynamic problems including two deformable solids in unilateral contact with Coulomb friction. The corresponding contact law is expressed on the contact interface between the two solids:

$$
\begin{aligned}
& \sigma_{n} \leq \mathbf{0} \quad\left(\text { contact } \quad \sigma_{n}<0 \quad \text { and separation if } \sigma_{n}=0\right) \\
& \left\|\sigma_{t}\right\| \leq \mu\left|\sigma_{n}\right| \\
& -\quad \text { si }\left\|\sigma_{t}\right\|<\mu\left|\sigma_{n}\right|, \quad v_{t}=0 \quad \text { (stick) } \\
& -\quad \text { si }\left\|\sigma_{t}\right\|=\mu\left|\sigma_{n}\right|, \quad \sigma_{n} \cdot v_{t} \leq 0 \quad \text { (slip) }
\end{aligned}
$$

$\sigma_{n}, \sigma_{t}$ are respectively contact normal and tangential contact stresses, $\mu$ is the constant friction coefficient, and $v_{t}$ local tangential relative velocity. For Finite Element simulations presented here, the discrete formulation with Lagrange multipliers is used. The finite element solution of the governing continuum mechanics equations is obtained by using the discretization procedures for the principle of virtual work and by discretizing the contact conditions (Baillet et al., 2005; Carpenter et al., 1991) yielding:

$$
\left\{\begin{array}{l}
\mathbf{M U}+\mathbf{C} \dot{\mathbf{U}}+\mathbf{K U}+\mathbf{G}^{T} \lambda=\mathbf{F} \\
\mathbf{G U} \leq 0
\end{array}\right.
$$

where $\mathbf{M}, \mathbf{C}$ and $\mathbf{K}$ are respectively symmetric and positively defined matrices of mass, Rayleigh's proportional damping $\left(\mathbf{C}=\alpha_{1} \mathbf{M}+\alpha_{2} \mathbf{K}\right)$ and stiffness of the system. $\mathbf{U}, \dot{\mathbf{U}}, \ddot{\mathbf{U}}$ are respectively the vectors of nodal displacements, nodal velocities and nodal accelerations. $\mathbf{F}$ is the vector of nodal external forces. $\lambda=\left[\lambda_{N} \lambda_{T}\right]^{\mathrm{T}}$ contains respectively normal and tangential forces at contact nodes. $\mathbf{G}$ is the global matrix of the displacement conditions ensuring non-penetration and the contact law of the bodies in contact (Carpenter et al., 1991).

Vibrations generated at contact and transmitted to the solids are presented in this paper through two applications. In the first one linear and non linear analyses are combined to understand physical phenomenon acting in friction-induced vibrations. In the second application, nonlinear temporal simulations allows a numerical investigation of the dynamic rupture of a bi-material interface.

\section{Study of friction-induced vibrations of beam-on-beam system}

When two bodies are in contact with friction, friction-induced vibrations can occur. These vibrations generated by friction are responsible for different noises and stress concentrations. In the case of automobile braking, these vibrations can generate groaning, squealing, humming and moaning and so forth. The complexity of the friction-induced vibration phenomenon drove us to study numerically and experimentally friction-induced vibrations of a model system. 


\subsection{Experimental results}

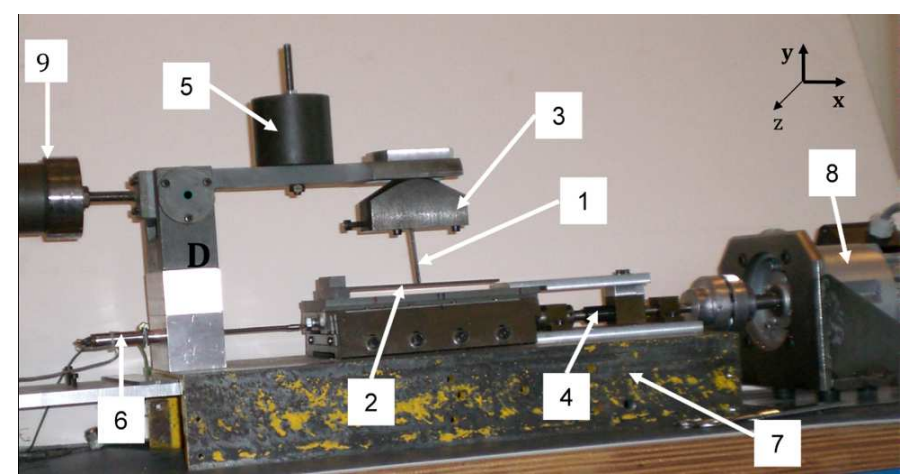

Figure 1. Experimental device: (1) Beam $P^{(1)}$, (2) beam $P^{(2)}$, (3) beam $P^{(1)}$ support, (4) screw-nut system, (5) weight, (6) displacement transducer, (7) frame, (8) DC motor, (9) counterweight

The bench used is shown in Figure 1. It is composed of three parts: a fixed part (I) connected to the ground composed of a frame (9) and a DC-motor (8); a part moving in translation (II) composed of the beam $\mathrm{P}^{(2)}(2)$ and its support, that can translate along the $\mathrm{x}$-axis in relation to the frame (7) via a screw-nut system (4) driven in rotation by a DC motor (8) ; and finally a part (III) composed of beam $\mathrm{P}^{(1)}$ (1), its support (3), the weight (5) corresponding to the application of a force of $9 \mathrm{~N}$ at point A (Figure 2), and a counterweight (10). The weight of assembly (3)+(1) is counterbalanced by (10) in order to apply the force only with the weight (5). This part free from rotation around the $\mathrm{z}$-axis at point $\mathrm{D}$. Beam $\mathrm{P}^{(1)}$ is clamped at its support and is in contact with beam $\mathrm{P}^{(2)}$ at point $\mathrm{C}$. As part (III) can rotate at point $\mathrm{D}$, beam $\mathrm{P}^{(1)}$ is free along an arc of a circle. Beam $\mathrm{P}^{(2)}$ is also clamped at its support (4) and free at its other extremity. A velocity $V$ along the $\mathrm{x}$-axis is imposed on the support of beam $\mathrm{P}^{(2)}$ by assembly (4)+(8).

In this experimental part, the friction-induced vibrations of two beams in contact whose dimensions are given in Table 1 are studied. Angle $\theta$, force $F$ and velocity $V$ are respectively fixed at $5^{\circ}, 9 \mathrm{~N}$ and $-2 \mathrm{~mm} / \mathrm{s}$. Measured friction coefficient is equal to 0.2 . For these set of parameters, the system exhibited intermittent periodic steady state vibrations (Figure 5). Fast Fourier Transform (FFT) of the measured vibrations showed that the frequency spectrum is periodic characterized by one main frequency $2700 \mathrm{~Hz}$ and its harmonics $5400 \mathrm{~Hz}$ and $8100 \mathrm{~Hz}$ (Figure 6). To understand these vibrating phenomena and the dynamic contact behaviour, a numerical study was performed. These studies are based on two types of analysis: complex eigenvalue analysis (linear) and dynamic transient analysis (non linear). 


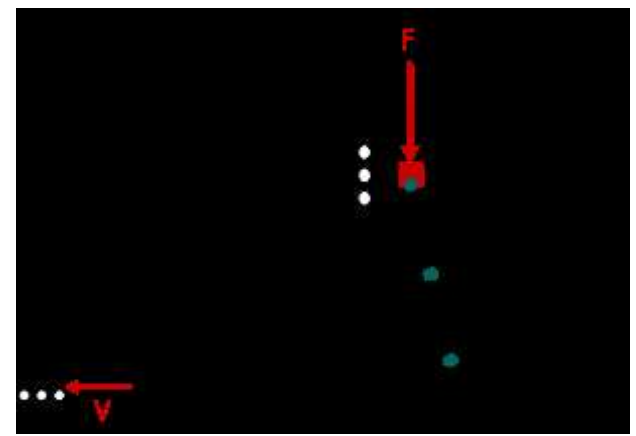

Figure 2. Representation of the model system studied. Initially, point $C$ is $80 \mathrm{~mm}$ from the clamp of beam $P^{(2)}$ for the numerical simulations and tests described. Concentrated mass. For the reference case: $V=-2 \mathrm{~mm} / \mathrm{s}, F=9 \mathrm{~N}$ and $\theta=5^{\circ}$

\subsection{Numerical study}

Figure 2 shows the model of the experimental system presented in Figure 1. The two steel beams $\mathrm{P}^{(1)}$ and $\mathrm{P}^{(2)}$ are in frictional contact. The contact surfaces are considered as being perfectly flat. The thermal and physicochemical effects are neglected. The mechanism governing $\mathrm{P}^{(1)}$ and $\mathrm{P}^{(2)}$ is modeled as a boundary condition. $\mathrm{P}^{(2)}$ is free-clamped. Point $\mathrm{A}$ of $\mathrm{P}^{(1)}$ is blocked in translation in the $\mathrm{x}$ direction and in rotation in the z-direction. The assembly $(3)+(9)+(5)$ is modelled by an equivalent concentrated mass $(3 \mathrm{Kg})$ whose value was determined during the study of the dynamics of the system (with $V=0 \mathrm{~mm} / \mathrm{s})(3 \mathrm{~kg})$. A force F was applied at point $\mathrm{A}$ in the $\mathrm{y}$-direction, corresponding to the force applied by the weight (5). $\mathrm{A}$ velocity $\mathrm{V}$ in the $\mathrm{x}$-direction was imposed at $\mathrm{P}^{(2)}$ at the clamp.

Table 1. Input data for the two beams $P^{(1)}$ et $P^{(2)}$

$\mathrm{P}^{(1)} \quad \mathrm{P}^{(2)}$

\begin{tabular}{lll}
\hline Dimensions & & \\
Length & $0.05 \mathrm{~m}$ & $0.15 \mathrm{~m}$ \\
Width & $0.01 \mathrm{~m}$ & $0.015 \mathrm{~m}$ \\
Thickness & $0.0015 \mathrm{~m}$ & $0.003 \mathrm{~m}$ \\
\hline Material & & \\
Density $(\rho)$ & $7900 \mathrm{~kg} / \mathrm{m}^{3}$ & $7900 \mathrm{~kg} / \mathrm{m}^{3}$ \\
Young Modulus(E) & $185 \mathrm{GPa}$ & $185 \mathrm{GPa}$ \\
Damping coefficient $\alpha_{1}$ & $50 \mathrm{~s}^{-1}$ & $50 \mathrm{~s}^{-1}$ \\
Damping coefficient $\alpha_{2}$ & $1 \cdot 10^{-8} \mathrm{~S}$ & $1 \cdot 10^{-8} \mathrm{~s}$ \\
Finite Element number & 30 & 90 \\
\hline
\end{tabular}




\subsubsection{Linear complex eigenvalue analysis (CEA)}

The following discussion focuses on the linear stability of the steady sliding equilibrium. Contact is treated by using Lagrange multipliers (Lorang et al., 2006). The complex and conjugate pairs of eigenvalues $\varphi_{i}$ of the perturbed system can be written as $\varphi_{i}=-\eta_{i} \omega_{i}+j \omega_{i}$ where $\omega_{i}$ is the $i^{\text {th }}$ angular frequency of the system. The existence of a non trivial eigenvector for several $\varphi_{i}$ with a strictly positive real part $\left(\eta_{i}<0\right)$ implies the instability of the steady sliding equilibrium: a divergence instability if $\omega_{i}=0$ (non-oscillatory) and a flutter instability if $\omega_{i} \neq 0$ (oscillatory) 0 . Attention is given here to flutter instability. It can be noted that a negative $\eta_{i}$ corresponds to negative equivalent damping coefficient.

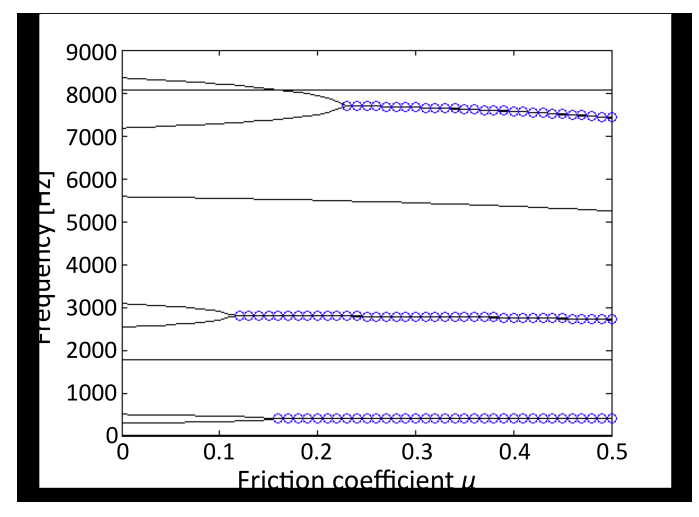

Figure 3. Complex eigenvalue analysis of the system studied: evolution of the frequency of the 10 first modes of the system coupled by friction versus Coulomb friction coefficient $\mu\left(F=9 N, \theta=5^{\circ}\right) . \bigcirc$ unstable frequencies $\left(\eta_{i}<0\right)$

Figure 3 shows the CEA of the system as a function of the friction coefficient. In the frequency domain considered $(<10 \mathrm{kHz})$ and for Coulomb friction coefficient $\mu$ between 0 and 0.5 , three mode coalescences $(400 \mathrm{~Hz}, 2800 \mathrm{~Hz}$ and $7700 \mathrm{~Hz}$ ) are observed at different critical friction coefficients: $\mu_{c}^{400 \mathrm{~Hz}}=0.16, \mu_{c}^{2800 \mathrm{~Hz}}=0.12$ and $\mu_{c}^{7700 \mathrm{~Hz}}=0.23$. The CEA predicts two eigenvalues with $\eta_{i}<0$ at $\mu=0.2$. The corresponding frequencies are $400 \mathrm{~Hz}$ and $2800 \mathrm{~Hz}$. This second frequency $(2800 \mathrm{~Hz})$ corresponds to the experimental fundamental frequency of vibration $(2700 \mathrm{~Hz}$ Figure 6). This confirms that the observed vibrations of the system come from a flutter instability phenomenon predicted by this linear analysis.

Figure 4 shows the 5 th and the 6 th eigenvalues in the complex plane. For a friction coefficient $\mu$ equal to zero both are far from the other $\left(\omega_{5}=2500 \mathrm{~Hz}\right.$ and $\left.\omega_{6}=3100 \mathrm{~Hz}\right)$. By increasing friction coefficient $\mu$ eigenvalues 5 and 6 move parallel to the imaginary axis until the lock-in $(\mu=0.12)$ (Akay et al., 2001), the limit point of stability, where $\omega_{5} \approx \omega_{6} \approx 2800 \mathrm{~Hz}$. As the friction coefficient $\mu$ still 
increases, one eigenvalue crosses the imaginary axis and becomes unstable $\left(\eta_{6}<0\right)$ and the other eigenvalue moves to the increasing but positive apparent damping coefficient $\eta_{5}$ (stable eigenvalue). The deformed shape of this mode (non presented here) exhibits considerable coupling between tangential and normal vibrations at the contact, which is known to be an important parameter of friction-induced instability (Akay et al., 2001).

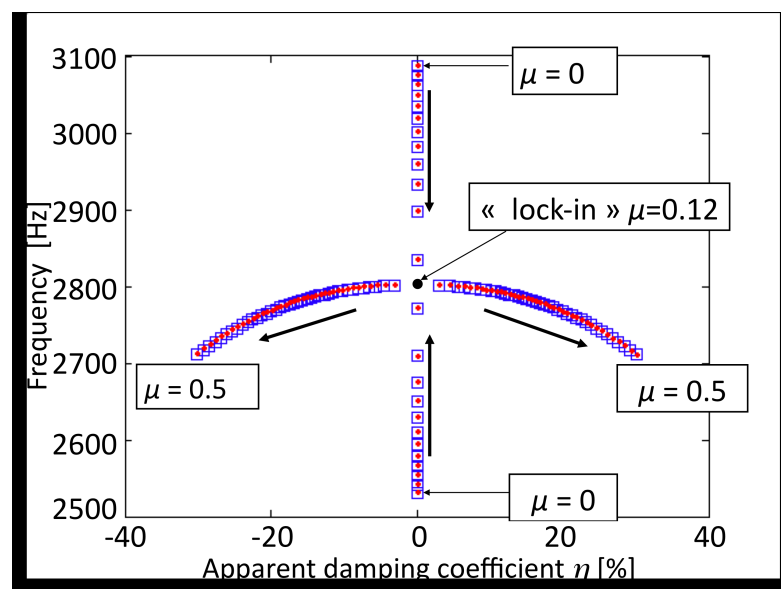

Figure 4. Evolution of the 5th and 6th eigenvalues as a function of friction coefficient $\mu$

This linear analysis provides an approach, which can explain the experimentally observed vibration phenomena as flutter instability of the system due to the contact. It corresponds to a phenomenon of lock-in (Akay et al., 2001) of two structure assembly modes.

Indeed the experimental results showed complex vibrating behaviour. To study the vibrations and the contact dynamics of the system during unstable behaviours and to complete linear analysis, a transient dynamic analysis that takes into account the non linear aspects (stick, slip, separation) of contact with friction is performed.

\subsubsection{Non linear transient analysis}

In this analysis, displacements, velocities and accelerations at the different nodes, as well as the values of the forces and contact node status (stick, slip, separation) are calculated through time. Equation of motion are discretized in time by a Newmark scheme of type $\beta_{2}$. 


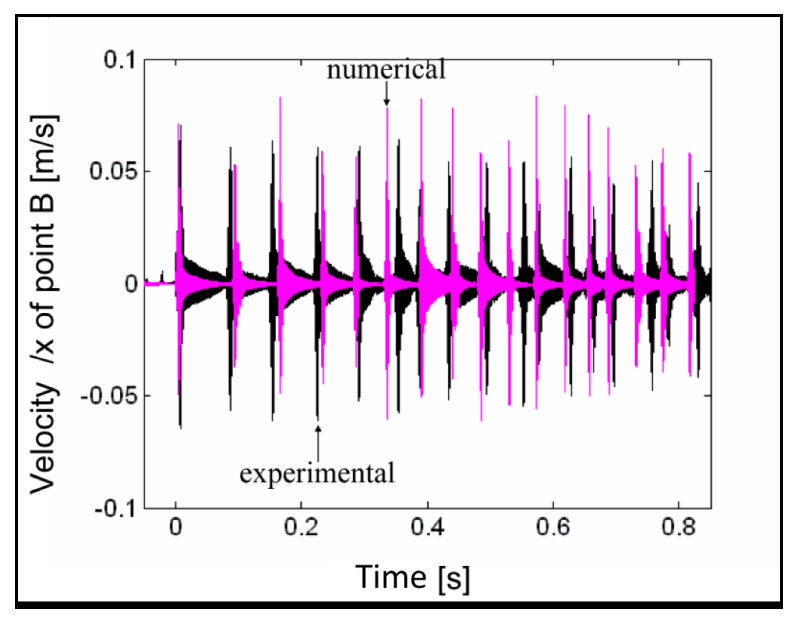

Figure 5. Numerical and experimental velocities in the $x$-direction of point $B$ versus time $\left(\mu=0.2, F=9 N, V=-2 \mathrm{~mm} / \mathrm{s}\right.$ et $\left.\theta=5^{\circ}\right)$

Figure 5 shows experimental and numerical velocities of point $B$ in time and in frequency for imposed velocity $V$ of $-2 \mathrm{~mm} / \mathrm{s}$. As in experimental results the system exhibits intermittent periodic steady state vibrations. This numerical analysis predicts the experimental trends observed previously. In spite of certain minimal differences the numerical and experimental signals in time and in frequency are close to each other. Thank to this good prediction, a local study of contact vibration is possible to understand physically these vibrations.

This intermittent phenomenon involves two phases: the system undergoes a phase of high level vibrations $\left(T_{v i b}\right)$ and a phase during which the vibrations attenuated and vanished $\left(T_{S t}\right)$ (Figure 7 ). During $T_{v i b}$, the system exhibits highfrequency vibrations at a frequency of $2700 \mathrm{~Hz}$ and the contact node successively sticks, slides and separates in comparison to the contact surface of $\mathrm{P}^{(2)}$. These vibrations are due to flutter instability of steady sliding equilibrium, as in Section 2.1. The normal contact force and the relative velocity between the two beams at the contact are represented on Figure 7 on a small time-scale and reach respectively $40 \mathrm{~N}$ $(F=9 \mathrm{~N})$ and $50 \mathrm{~mm} / \mathrm{s}(V=-2 \mathrm{~mm} / \mathrm{s})$. The contact conditions are much severer than expected. Then during $T_{S t}$ the magnitude of high-frequency vibration decreases, whereas the slave node sticks to the surface of beam $\mathrm{P}^{(2)}$ (Figure 5). This kind of vibration can be associated to the Stick-Slip phenomenon (Mills, 1938). In our configuration, the imposed friction coefficient is constant and the vibrations correspond to a limit cycle including stick-slip-separation in the contact zone. 


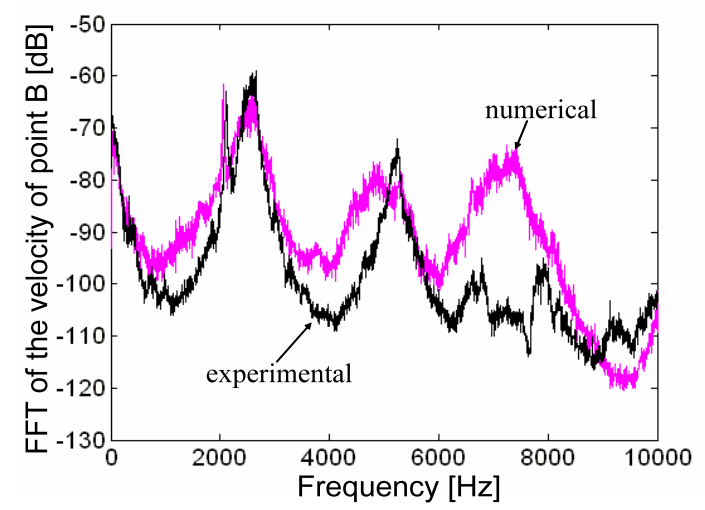

Figure 6. FFT of numerical and experimental velocities in the $x$-direction of point $B$ (Figure 2) $\left(\mu=0.2, F=9 \mathrm{~N}, V=-2 \mathrm{~mm} / \mathrm{s}\right.$ et $\left.\theta=5^{\circ}\right)$

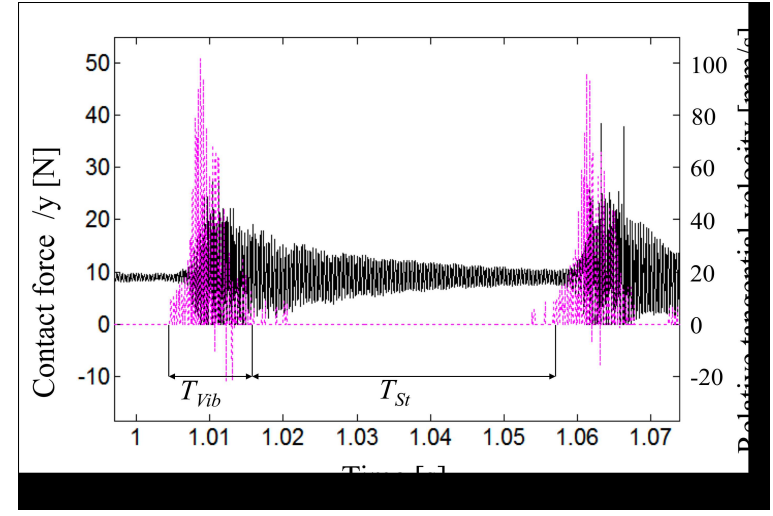

Figure 7. Contact force in y-axis (solid line) and relative tangential velocity (dash line). Results from numerical time domain simulation with $\mu=0.2, V=-2 \mathrm{~mm} / \mathrm{s}, \quad F$ $=9 \mathrm{~N}$ and $\theta=5^{\circ}$

It has been showed that complex eigenvalue and transient dynamic analyses (performed in parallel) could predict the level and type of vibration frequency with accuracy and they explain the physical phenomena involved in friction-induced vibrations such as contact dynamics and the importance of coupling between tangential and normal vibrations at the contact. 


\section{Rupture velocity in pre-stressed interface (ModeII)}

Understanding wave generation and propagation from contact interfaces is a substantial subject of interest for researchers involved on several domains such as tribology, geophysics, dynamics, ect. The different ruptures can be classified depending on the velocity of their front (Shi et al., 2007): (i) Sub-shear type: the velocity of the rupture front is less than the shear wave velocity; (ii) super-shear type: the velocity of the rupture front is more than the shear wave. They can also be classified depending on the interface states (Shi et al., 2007): (j) Pulse-like rupture: only a small part of the broken interface is in sliding state; (jj) Crack-like rupture: the broken part of the interface is sliding continuously.

\subsection{Numerical model description}

The two-dimensional in-plane dynamic rupture model consists of two different isotropic elastic media separated by an interface governed by Coulomb friction law (Friction coefficient equal to 1). PLAST2 in (2D) (Baillet et al., 2005), an semiimplicit dynamic finite element code, is used to simulate the behaviour of the system $\left(\mathrm{P}^{(1)}\right.$ and $\left.\mathrm{P}^{(2)}\right)$ during frictional contact. It uses a forward Lagrange multiplier method 0 for the contact between deformable bodies. Table 2 shows the parameters of the materials used in these simulations. A « rupture » is considered when an initially sticking zone of the interface $\left(|| \sigma_{t}||<\mu\left|\sigma_{n}\right|\right)$ is becoming in sliding state $\left(|| \sigma_{t} \|=\mu\left|\sigma_{n}\right|\right)$

Table 2. Dimension and material parameters of both solids. Contrast between the two materials (defined by the ratio between shear wave velocities) is fixed at 0.9

Solid 1

\begin{tabular}{lcc}
\hline Dimensions & & \\
Length & $20 \mathrm{~mm}$ & $20 \mathrm{~mm}$ \\
Width & $5 \mathrm{~mm}$ & $5 \mathrm{~mm}$ \\
Matérial & & \\
Young modulus & $5.3 \mathrm{GPa}$ & $3.392 \mathrm{GPa}$ \\
Density & $1246 \mathrm{~kg} / \mathrm{m}^{3}$ & $1246 \mathrm{~kg} / \mathrm{m}^{3}$ \\
Poisson ratio & 0.25 & 0.25 \\
Wave velocities & & \\
Dilatationnal wave & & $1940 \mathrm{~m} / \mathrm{s}$ \\
Shear wave & $2430 \mathrm{~m} / \mathrm{s}$ & $1120 \mathrm{~m} / \mathrm{s}$ \\
Rayleigh wave & $1270 \mathrm{~m} / \mathrm{s}$ & $950 \mathrm{~m} / \mathrm{s}$ \\
\hline
\end{tabular}

Solid 2

The first step of the simulation consists in pressing together the two bodies by a global normal force $\mathrm{N}$ applied on the external surfaces, and subjected to a shearing 
force $\mathrm{T}$ which is calculated to be just less than the required one to produce slipping. To obtain this forces the superior surface of the body $P^{(l)}$ is fixed and the inferior surface of the body $P^{(2)}$ is shifted by the opportune amounts $\mathrm{u}_{0}$ in the $\mathrm{x}$ direction and $\mathrm{v}_{0}$ in the $\mathrm{y}$ direction.

In a second step, rupture is initiated in the "nucleation" zone at the center of the interface, by decreasing instantaneously the friction coefficient to zero for a defined number of contact nodes $L_{n u c}$ (length of nucleation zone) in such a way a mode II rupture can be initiated (the slip is parallel to the direction of rupture propagation).

\subsection{Results}

Elastic energy released during nucleation gives rise to two ruptures propagating in opposite senses (Figure 8). Figure 9 shows cumulative sliding profile for a central nucleation of length $L_{\text {nucl }}=0.125 \mathrm{~mm}$.

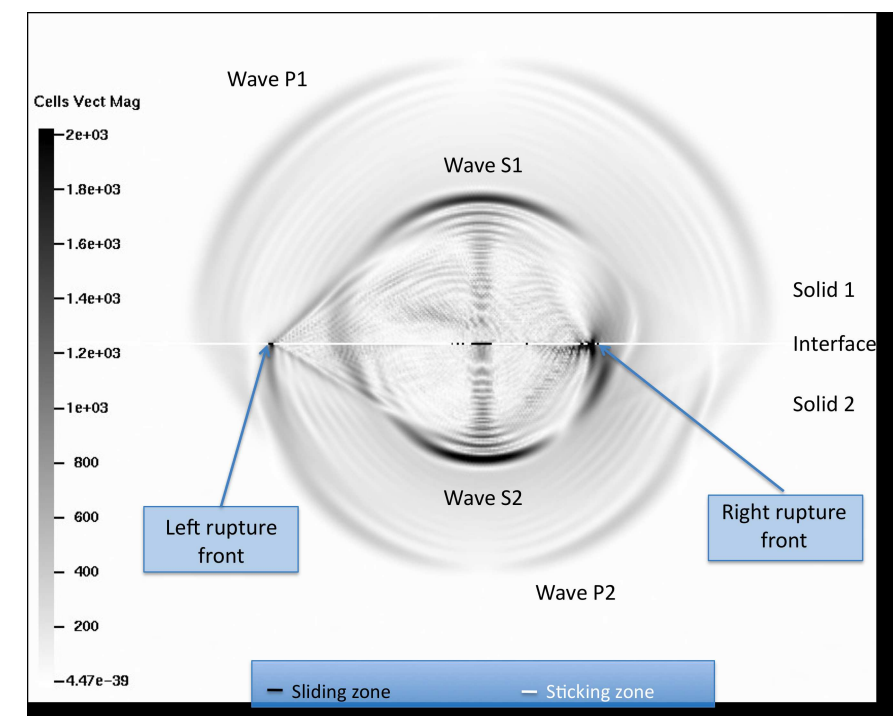

Figure 8. Iso-values of velocity in solids 1 and 2 (at the interface white line = sticking $\left\|\sigma_{t}\right\|<\mu\left|\sigma_{n}\right|$ and black line $=$ sliding $\left.\left\|\sigma_{t}\right\|=\mu\left|\sigma_{n}\right|\right)$

Figure 8 represents the isovalues of velocity of the two bodies in contact. Waves generated by the nucleation are identified: $\mathrm{P}$ waves and $\mathrm{S}$-waves in both solids and the generalized Rayleigh wave at the interface. As the wave velocities are different in solids 1 and 2, the nucleation induced different displacement on opposite side of the interface, causing asymmetrical rupture behaviour around nucleation zone. 
From the nucleation, a supershear pulse-like rupture is propagating to the left. The Mach cone at the rupture front (Figure 8) is characteristic of supershear rupture. The rupture front is staying at the $\mathrm{x}$ position of $8.7 \mathrm{~mm}$. It corresponds to an evanescent supershear rupture, propagating at a velocity $\left(c_{\mathrm{RUP}} \approx 1700 \mathrm{~m} / \mathrm{s}\right)$ near to the slowest P-wave velocity of the two materials. From cumulative sliding profile in Figure 9, it can be seen that after sliding induced by front arrival, the sliding stops and after a short sliding time the contact zone is self-healing (sticking again). Along propagation, the sliding distance at the interface is decreasing causing the evanescence of the rupture. The right-hand rupture is a self-sustained sub-Rayleigh rupture. The velocity of rupture front is $980 \mathrm{~m} / \mathrm{s}$ (near to $c_{R 2}$ ). From Figure 8 it can be seen that the rupture is also self-healing. It corresponds to the propagation of a sliding pulse in self-sustained manner as the sliding distance is increasing along propagation. The obtained velocities of the two ruptures are conform to the results obtained analytically by Adams (2001).

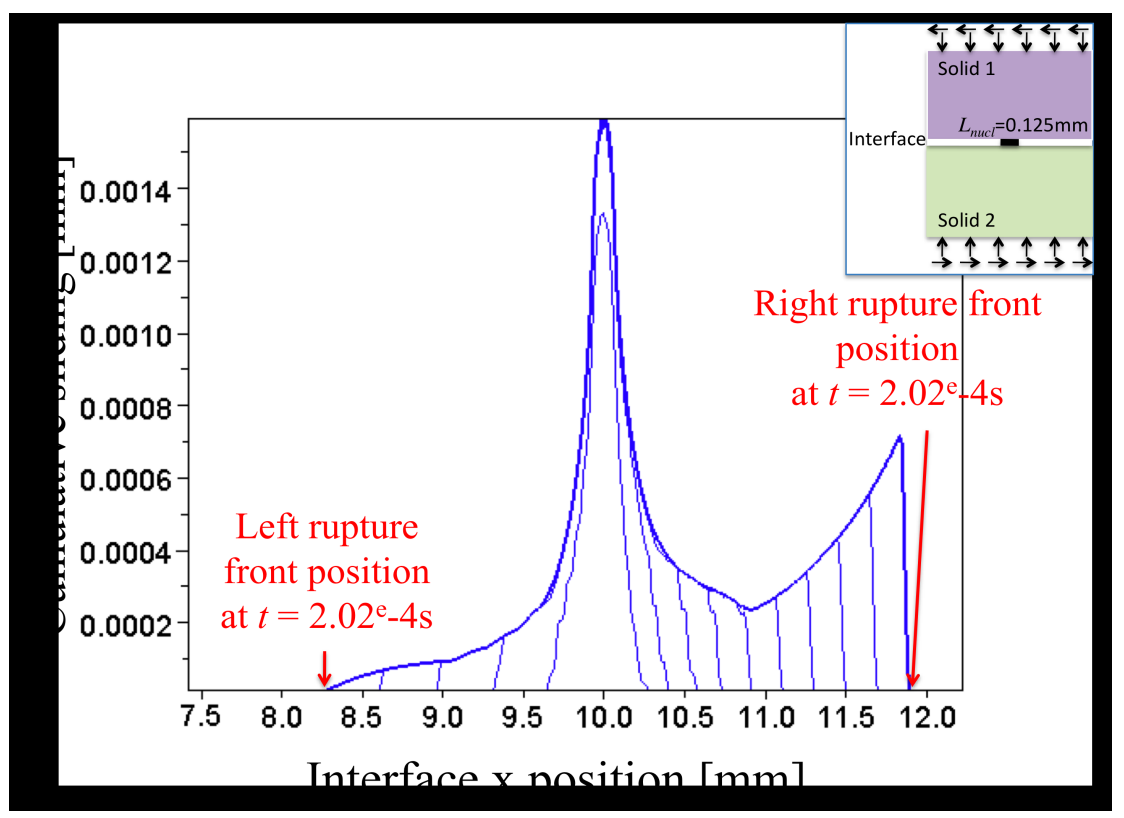

Figure 9. Cumulative sliding versus $x$ position on the interface (representation of cumulative sliding at the interface each $0.2 \mu \mathrm{s}$ from $0.2 \mu \mathrm{s}$ to $2.02 \mu \mathrm{s}, L_{\text {nucl }}=0.125 \mathrm{~mm}$ centered around $10 \mathrm{~mm}$ ) 


\section{Conclusion}

In this paper we proposed a non linear transient analysis which gives the temporal evolution of displacement, velocity, acceleration of the different nodes of the system. Moreover all contact values (stress, kinematic state, displacement) are given, which enable a local contact study of the phenomenon. In the first application, numerical study of friction-induced vibrations observed experimentally. Linear analysis provides the origin of the vibrations and is completed by non linear transient analysis explaining local phenomenon driving to friction-induced vibrations. In the second application, numerical results obtained described dynamical rupture of two solids initially prestressed. The different types of ruptures can be obtained by the model with a Coulomb friction law. Numerical simulations presented here provide all data for the study of waves generated by dynamic ruptures.

\section{References}

Adams G.G., "An intersonic slip pulse at a frictional interface between dissimilar materials", Journal of Applied mechanics, 68, 2001, 81-86.

Akay A., Wickert J., Xu Z., "Investigation of mode lock-in and friction interface", Final Report, Department of mechanical engineering, Carnegie Mellon University, Pittsburgh, 2000.

Baillet L., Sassi T., « Mixed finite element formulation in large deformation frictional contact problem », Revue Européenne des Eléments Finis, vol. 14, n² 2-3, 2005, 287-304.

Carpenter N. J., Taylor R. L., Kantona M. G., "Lagrange contrainsts for transient finite element surface contact", Int. J. Numerical Methods Engineering, vol. 32, 1991, 103-128.

Cochard A., Rice J.R., "Fault rupture between dissimilar materials: Illposedess, regularization and slip-pulse response", Journal of Geophysical Research, 105, 25, 2000, 891.

Lorang X., Foy-Margiocchi F., Nguyen Q.S., "Gautier P.E., TGV disc brake squeal”, Journal of Sound and Vibration, 293, 2006, 735-746.

Mills H.R., Brake Squeak, Institution of Automobile Engineers, 1938.

Nguyen Q.S., Instability and friction, Compte rendus de Mécanique, 331(1), 2003, 99-112.

Shi Z., Ben-Zion Y., Needleman A., "Properties of dynamic rupture and energy partition in a solid with a frictional interface", Journal of Mechanics and Physics of Solids, 56 5-24, 2007.

Vola D., Raous M., Martins J.A.C., "Friction and instability of steady sliding: squeal of a rubber/glass contact", International Journal for Numerical Methods in Engineering vol. $46, \mathrm{n}^{\circ} 10,1999,1699-1720$. 